donc une régulation presque parfaite de la sécrétion des peptides, respectant la localisation et le rythme pulsatile de celle-ci. Ce succès contraste avec les effets des greffes de tissu foetal préoptique [4] : les greffes, faites il est vrai chez l'adulte, restaurent le phénotype normal, mais ne restaurent ni des cycles convenables chez la femelle ni la fertilité chez le mâle. Le travail très brillant que nous venons de résumer ouvre la voie à d'importants développements : définition précise des rôles des peptides GnRH et GAP, et surtout production d'animaux hpg transgéniques contenant des mutations dans la partie qui code pour GnRH ou GAP.

J.-C.D.

1. Cattanach BM, Iddon CA, Charlton HM, Chiappa SA, Fink G. Gonadotrophin-releasing hormone deficiency in a mutant mouse with hypogonadism. Nalure $1977 ; 269: 338-40$. 2. Mason AJ, Hayflick JS, Zoeller RT, et al. A deletion truncating the gonadotrophinreleasing hormone gene is responsible for hypogonadism in the hpg mouse. Science 1986 234: 1366-71.

3. Mason AJ, Pitts SL, Nikolics K, et al. The hypogonadal mouse : reproductive functions restored by gene therapy. Science $1986 ; 234$ $1372-8$.

4. Gibson MJ, Krieger DT, Charlton HM, et al. Mating and pregnancy can occur in genetically hypogonadal mice with preoptic area brain grafts. Science $1984 ; 225: 949-51$.

\section{BRÈVES}

La surinfection par le virus herpès de lymphocytes $T$ $\mathrm{CD}_{4}(+)$ infectés par HIV (agent du SIDA) peut induire la transcription du génome rétroviral, et donc activer une infection latente par HIV. Le mécanisme en serait la stimulation de séquences régulatrices du LTR rétroviral intégré dans l'ADN de la cellule infectée par une protéine " active en trans" codée par le virus herpès. Un tel mécanisme indique qu'une infection par un virus herpès d'un porteur sain d'HIV peut déclencher l'entrée dans la maladie.

[Mosca et al. Nature 1986 ; 325 : 67-70.]

$m / s n^{\circ} 4$ vol. 3, aoril 87

\title{
口ם BRÈVES
}

L'hyperexpression d'oncogènes cellulaires dans des souris transgéniques peut provoquer des anomalies du développement et de la maturation de certains tissus. c-fos est l'oncogène cellulaire homologue du gène transformant de plusieurs espèces de rétrovirus murins responsables du développement d'ostéosarcomes.

Lorsqu'une cellule est stimulée, cfos se met rapidement à proliférer, le contrôle de son expression étant transcriptionnel (par l'intermédiaire d'un " enhancer " régulé par les facteurs de croissance du sérum) et post-transcriptionnel, via la possible destabilisation du messager due à la reconnaissance par des protéines d'un élément situé dans la région $3^{\prime}$ non codante. Des souris transgéniques exprimant le gène $c$-fos sous le contrôle de différents types de promoteurs ont été créées; le messager du transgène est délété dans sa partie 3 ' et est donc stable . L'hyperexpression de c-fos dans différents organes des animaux transgéniques et de leur descendance n'entraîne aucune tumeur, mais des malformations osseuses combinant une augmentation de la résorption ostéoclastique et l'apposition d'os nouveau en rapport avec une stimulation ostéoblastique [1]. Voici quelques mois, une autre équipe avait montré que l'hyperexpression de c-myc dans les lymphocytes B d'animaux transgéniques créés par l'injection du gène $c$-myc placé sous le contrôle du "enhancer" des chaînes lourdes d'immunoglobuline, entraînait des perturbations du développement des lignées lymphocytaires B [2]. Tous ces résultats démontrent que les oncogènes cellulaires sont impliqués in vivo dans le développement normal des tissus.

[1. Rüther U et al. Nature 1987 ; 325 : 412-6.]

[2. Langdon WY et al. Cell 1986, 47 : 11-8.]
Le facteur VIII ou antihémophilique $\mathbf{A}$ est une molécule de très grande taille. Ses 2332 acides aminés sont répartis en trois types de domaines $A, B, C$; le domaine $\mathrm{B}$, hautement glycosylé, disparaît lors de l'activation protéolytique du facteur VIII par la thrombine. Les chercheurs de Genentech, qui avaient déjà réalisé son clonage, ont obtenu par les méthodes de recombinaison de l'ADN une construction dans laquelle la plus grande partie du domaine $B$ est délétée, puisqu'il passe de 909 à 142 acides aminés. Exprimé dans des cellules de mammifères, ce facteur VIII raccourci est activé par la thrombine et se fixe sur le facteur Willebrand comme son homologue " normal ". C'est la première étape vers la fabrication du " minifacteur VIII " recombinant actif, objectif que nous annoncions dès le $n^{\circ} 1$, vol. 1, p. 50 de m/s.

[Eaton DA, et al. Biochemistry $1986 ; 25: 8343-7$.

- Probablement du fait des nombreuses anomalies génétiques qui lui sont rattachées, le chromosome $\mathrm{X}$ a fait récement l'objet d'études multiples pour détecter des polymorphismes de restriction à l'aide de sondes appropriées. On a pu en tirer l'impression que sa variabilité génétique était plus grande que celle des autosomes. On a donc comparé le nombre de polymorphismes de restriction trouvés sur 17 autosomes et sur l'X en employant des sondes digérées par six enzymes de restriction. En réalité, la fréquence des polymorphismes s'est montrée trois fois moindre sur le chromosome $\mathrm{X}$ que sur l'ensemble des autosomes, et les auteurs vont jusqu'à suggérer que l'X serait en fait une " niche de mutation basse".

[Hofker MH, et al. Am J Hum Genet 1986 ; 39 : 438-51.]
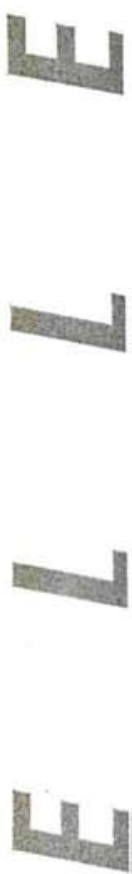

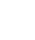
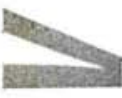